\title{
A Review of Non-Alcoholic Fatty Liver Disease in HIV- Infected Patients: The Next Big Thing?
}

\author{
Berend J. van Welzen (D) - Tania Mudrikova - Ayman El Idrissi •
}

Andy I. M. Hoepelman · Joop E. Arends

Received: October 11, 2018 / Published online: January 3, 2019

(C) The Author(s) 2019

\section{ABSTRACT}

The burden of liver-related morbidity remains high among HIV-infected patients, despite advances in the treatment of HIV and viral hepatitis. Especially, the impact of non-alcoholic fatty liver disease (NAFLD) is significant with a prevalence of up to $50 \%$. The pathogenesis of NAFLD and the reasons for progression to non-alcoholic steatohepatitis (NASH) are still not fully elucidated, but insulin resistance, mitochondrial dysfunction and dyslipidemia seem to be the main drivers. Both HIVinfection itself and combination antiretroviral therapy (cART) can contribute to the development of NAFLD/NASH in various ways. As ongoing HIV-related immune activation is associated with insulin resistance, early initiation of cART is needed to limit its duration. In addition, the use of early-generation nucleoside reverse transcriptase inhibitors and protease inhibitors is also associated with the development of NAFLD/NASH. Patients at risk should therefore receive antiretroviral drugs with a

Enhanced digital features To view enhanced digital features for this article go to https://doi.org/10.6084/ m9.figshare.7491617.

B. J. van Welzen ( $₫) \cdot$ T. Mudrikova · A. El Idrissi ·

A. I. M. Hoepelman · J. E. Arends

Department of Internal Medicine and Infectious

Diseases, University Medical Center Utrecht

(UMCU) Utrecht, Utrecht, The Netherlands

e-mail: B.J.vanWelzen@umcutrecht.nl more favorable metabolic profile. Only weight reduction is considered to be an effective therapy for all patients with NAFLD/NASH, although certain drugs are available for specific subgroups. Since patients with NASH are at risk of developing liver cirrhosis and hepatocellular carcinoma, several non-antifibrotic and antifibrotic drugs are under investigation in clinical trials to broaden the therapeutic options. The epidemiology and etiology of NAFLD/NASH in HIV-positive patients is likely to change in the near future. Current guidelines recommend early initiation of cART that is less likely to induce insulin resistance, mitochondrial dysfunction and dyslipidemia. In contrast, as a result of increasing life expectancy in good health, this population will adopt the more traditional risk factors for NAFLD/NASH. HIVtreating physicians should be aware of the etiology, pathogenesis and treatment of NAFLD/ NASH in order to identify and treat the patients at risk.

Keywords: Antiretroviral therapy; Fibrosis; HIV; NASH; Non-alcohol fatty liver disease

\section{INTRODUCTION}

In the current era of combination antiretroviral therapy (cART), the all-cause mortality in human immunodeficiency virus (HIV)-infected 
patients is low [1]. However, liver-related complications remain one of the major causes of mortality in this population [2]. Although viral hepatitis and excessive alcohol consumption are traditionally considered the most important causes of liver fibrosis and cirrhosis in HIV-infected patients, metabolic liver disease-mostly non-alcoholic fatty liver disease (NAFLD)—is increasingly recognized as an aetiological factor in the development of liver disease [2-5]. In fact, due to the introduction of effective therapies against viral hepatitis, it is likely that fatty liver disease will become the leading cause of liver cirrhosis in HIV-infected patients, as is already happening in the general population [6]. It should not be forgotten that NAFLD can coexist with other liver diseases, which will lead to faster progression of fibrosis towards endstage liver disease.

The term NAFLD encompasses a wide spectrum of entities ranging from 'simple' steatosis to non-alcoholic steatohepatitis (NASH) [7]. Since the major risk factors for NAFLD-insulin resistance [8, 9], mitochondrial dysfunction [10] and concurrent viral infections [11]—are highly prevalent in HIV-infected patients, this population is at risk for liver-related morbidity.

In this review, we describe the epidemiology and pathogenesis of NAFLD in HIV-infected patients. We also discuss the future with respect to novel (antiretroviral) medication and antiNAFLD interventions. This article is based on previously conducted studies and does not contain any studies with human participants or animals performed by any of the authors.

\section{EPIDEMIOLOGY}

The worldwide prevalence of NAFLD varies greatly among different geographical areas, with the highest numbers in northern America and the lowest in Africa; overall prevalence is estimated to be around 25\% [12]. In addition to many epidemiological studies in the general population, several studies describe the prevalence in a general HIV-infected population, with a prevalence varying from 28 to $48 \%$ [13-18]. In the meta-analysis by Maurice et al., the prevalence of imaging-based diagnosis of
NAFLD was $35 \%$, which is higher than the general population [19]. In patient populations with persistent liver enzyme elevations, the prevalence is even higher with approximately three-quarters of the patients having NAFLD [20-24] (Table 1). However, Price et al. performed a matched-control study which surprisingly showed a higher prevalence of NAFLD in the HIV-negative control group compared to their HIV-positive counterparts (19\% vs. $13 \%$, $P=0.02)$ [25]. This prevalence will be an underestimation of the 'real-life' prevalence due to exclusion of patients with a history of cardiovascular surgery and those with severe excess body weight. In another report, the imagingbased prevalence of NAFLD in a small cohort of HIV-positive patients was compared with HIVnegative controls [26]. The prevalence of steatosis tended to be higher among HIV-infected men compared to HIV-negative men (41\% vs. $33 \%$; not statistically significant), but was lower in HIV-positive versus HIV-negative women (17\% vs. 33\%). Both studies showed that classic risk factors-such as obesity-related insulin resistance-were the most important determinants for the development of NAFLD; HIV-related factors certainly contributed to this risk but its impact appeared to be limited. Therefore, it remains difficult to draw conclusions from these small studies because of methodological issues and small sample sizes; larger cross-sectional studies are thus needed.

\section{DIAGNOSIS}

The gold standard in diagnosing NAFLD is liver biopsy by which discrimination between steatosis and NASH is possible [27]. Given its invasive nature with risks such as haemorrhagic complications and pain, liver biopsy is not useful as an epidemiological screening tool [28]. As a result, current cross-sectional epidemiological data are mainly based on surrogate markers such as imaging rather than on histopathological data. Considering the higher sensitivity, lower costs and wide availability, ultrasound is preferred over CT-scanning for diagnosing NAFLD [29]. However, its sensitivity is limited in the setting of mild NAFLD and in 
Table 1 Overview of epidemiological studies describing the prevalence of NAFLD in HIV-infected patients

\begin{tabular}{|c|c|c|c|}
\hline Author and country & Population characteristics & $\begin{array}{l}\text { Diagnostic } \\
\text { test }\end{array}$ & $\begin{array}{l}\text { NAFLD } \\
\text { prevalance }\end{array}$ \\
\hline \multicolumn{4}{|c|}{ Studies describing the prevalence of NAFLD in a general HIV-positive population } \\
\hline $\begin{array}{l}\text { Guaraldi et al. [15], } \\
\text { Italy }\end{array}$ & $\begin{array}{l}n=225 . \text { Mean BMI: } 23.8 \\
\text { Consecutive patients evaluated in metabolic clinic }\end{array}$ & CT-scan & $36.9 \%$ \\
\hline $\begin{array}{l}\text { Crum-Cianflone } \\
\text { et al. [14], USA }\end{array}$ & $\begin{array}{l}n=216 . \text { Mean BMI: } 26.0 \\
\text { Consecutive patients in American military clinic }\end{array}$ & Ultrasound & $31.0 \%$ \\
\hline $\begin{array}{l}\text { Macias et al. [13], } \\
\text { Spain }\end{array}$ & $\begin{array}{l}n=505 . \text { Median BMI: } 23.2 \\
\text { Consecutive patients under follow-up in } 5 \text { different clinics }\end{array}$ & CAP & $40.0 \%$ \\
\hline $\begin{array}{l}\text { Nishijima et al. [17], } \\
\text { Japan }\end{array}$ & $\begin{array}{l}n=435 . \text { Mean BMI: } 22.8 \\
\text { All HIV-infected patients that underwent ultrasound between } \\
\text { 2004-2013. HBV\&HCV co-infection excluded }\end{array}$ & Ultrasound & $31.0 \%$ \\
\hline $\begin{array}{l}\text { Lui et al. [16], } \\
\text { China }\end{array}$ & $\begin{array}{l}n=80 . \text { Mean BMI: } 23.6 \\
\text { Consecutive patients under follow-up in ID clinic }\end{array}$ & MRS & $28.8 \%$ \\
\hline $\begin{array}{l}\text { Vuille-Lessard et al. } \\
\text { [18], Canada }\end{array}$ & $\begin{array}{l}n=300 . \text { Mean BMI: } 26.6 \\
\text { Consecutive patients under follow-up in ID clinic }\end{array}$ & CAP & $48.0 \%$ \\
\hline
\end{tabular}

Studies describing the prevalence of NAFLD in HIV-patients with persistent liver enzyme elevations
Lemoine et al. [23], $n=14$. Mean BMI: 23.0
Liver biopsy $57.1 \%$
France $\quad$ HIV-mono infection with ALT levels $\geq 2 \times$ ULN over 3 months
Ingiliz et al. [20],
$n=60$. Mean BMI: 23.0
Liver biopsy $60.0 \%$
France
ALT or AST $>2 \times$ ULN on two occasions in previous 6 months
Sterling et al. [22], $\quad n=14$. Mean BMI: 29.9
Liver biopsy $\quad 64.3 \%$
USA
AST or ALT $1.25-5 \times$ ULN over $\geq 6$ months
Morse et al. [21], $n=62$. Mean BMI: 28.0
Liver biopsy $72.6 \%$
USA
ALT or AST > ULN on three occasions in previous 6 months
Lombardi et al. [24], $n=66$. Mean BMI: Not available
Ultrasound $\quad 71.0 \%$
UK Retrospective cohort analysis of patients with ALT or AST > ULN
on two occasions in 6 months

$A L T$ alanine aminotransferase, $A S T$ aspartate aminotransferase, $B M I$ body-mass index, $C A P$ controlled attenuation parameter, $I D$ infectious diseases, $H B V$ hepatitis B virus, $H C V$ hepatitis $\mathrm{C}$ virus, $M R S$ magnetic resonance spectroscopy, $N A F L D$ non-alcoholic fatty liver disease, UK United Kingdom, ULN upper limit of normal, USA United States of America

morbidly obese patients [30, 31]. Magnetic resonance spectroscopy proton density fat fraction (MRS-PDFF) is a very sensitive imaging modality, with a sensitivity up to $100 \%$ [31]. Due to its wider availability and low risk for sampling error, magnetic resonance imaging proton density fat fraction (MRI-PDFF) is increasingly used in research. In a recent review by Caussy 
et al., the differences and impact of MRS-PDFF and MRI-PDFF were extensively discussed. Considering the high costs and limited availability, MRI-based imaging is currently still not a useful screening tool and its use remains limited to research [32]. In 2010, a new noninvasive tool for the detection of steatosis, called controlled attenuation parameter (CAP), was introduced [33]. It is an addition to the Fibroscan (Echosens, Paris, France) and measures steatosis simultaneously with fibrosis. CAP determines the total ultrasonic attenuation at a frequency of $3.5 \mathrm{MHz}$ and is reported in decibel/ meter $(\mathrm{dB} / \mathrm{m})$. In a meta-analysis by Wang et al., CAP provided good sensitivity and specificity [34]. For example, the sensitivity for the detection of $\geq S 1$ steatosis ( $\geq 5 \%$ of the hepatocytes affected with lipid accumulation) was 0.78 with an area under the curve (AUC) of 0.86 (95\% CI $0.82-0.88$ ). For stage S3 (> 66\% of the hepatocytes affected), the sensitivity was 0.86 with an AUC of 0.94 (95\% CI 0.91-0.96). It should be emphasized that none of the above-mentioned imaging modalities can assess the degree of NAFLD/NASH as assessed by the histological Brunt classification [35]. Differentiating between NAFLD and NASH is important since $25-35 \%$ of patients with NASH eventually progress to liver fibrosis or even cirrhosis [36, 37]. Using serum alanine aminotransferase (ALT) levels in addition to imaging to discriminate between steatosis and NASH turns out to be disappointing. Several studies showed that a significant proportion of the patients with biopsy-proven NASH had normal ALT values, although some studies suggested that the common laboratory cut-off value for ALT was too high [38-40]. There are several risk scores—such as the NAFLD Fibrosis score-available to evaluate which patients with NAFLD are at risk for (advanced) fibrosis, but its utility still needs to be evaluated in the HIV-positive population [41]. There are currently no guidelines that recommend universal screening for NAFLD in the general population or in specific subpopulations. In contrast, the European AIDS Clinical Society (EACS) guideline recommends screening for NAFLD in HIV-infected patients with metabolic syndrome using ultrasound [42]. Since the prevalence of NAFLD among HIV- infected patients with persistent liver enzyme elevations is high, ultrasound screening should also be considered in this population.

\section{PATHOGENESIS}

NAFLD is a clinical-histological diagnosis characterized by the presence of fat accumulation in hepatocytes resulting in necro-inflammation and hepatocyte ballooning in the absence of excessive alcohol use [43]. According to the American Association for the Study of Liver Diseases (AASLD), the threshold of 'significant alcohol consumption' is $>21$ standard drinks per week on average for men and $>14$ standard drinks on average in woman when evaluating patients with suspected NAFLD [44]. In general, NAFLD is considered to be the hepatic manifestation of the metabolic syndrome. The study of Mellinger et al. showed an association between presence of NAFLD and coronary artery calcium [OR $1.20(1.10-1.30) \quad P<0.001][45]$. This finding was confirmed in the HIV-positive population in the study of Crum-Cianflone et al., showing that high coronary artery calcification values are associated with the presence of steatosis [46]. Although the natural history of steatosis is usually benign, approximately $10 \%$ of patients with 'simple' steatosis progress to NASH. Eventually, 25-35\% of the patients with NASH progress to liver fibrosis or even cirrhosis. Eventually, $10 \%$ of patients with cirrhosis develop hepatocellular carcinoma (HCC) over a period of several years [36, 37] (Fig. 1).

Insulin resistance (IR) is considered to be the key mechanism in the development of steatosis [47]. IR contributes to hepatic triglyceride accumulation in two ways. First, insulin normally suppresses the activity of hormone-sensitive lipase (HSL). HSL is present in all adipocytes and is able to hydrolyse stored triglycerides into free fatty acids (FFAs) [48]. In the case of IR, the suppression of HSL is diminished, resulting in an increased hydrolysis in peripheral adipose tissue and therefore an increase in delivery of FFAs to the liver [49]. In the liver, the FFAs undergo esterification into triglycerides contributing to the process of steatosis. Second, the synthesis of lipids in the 


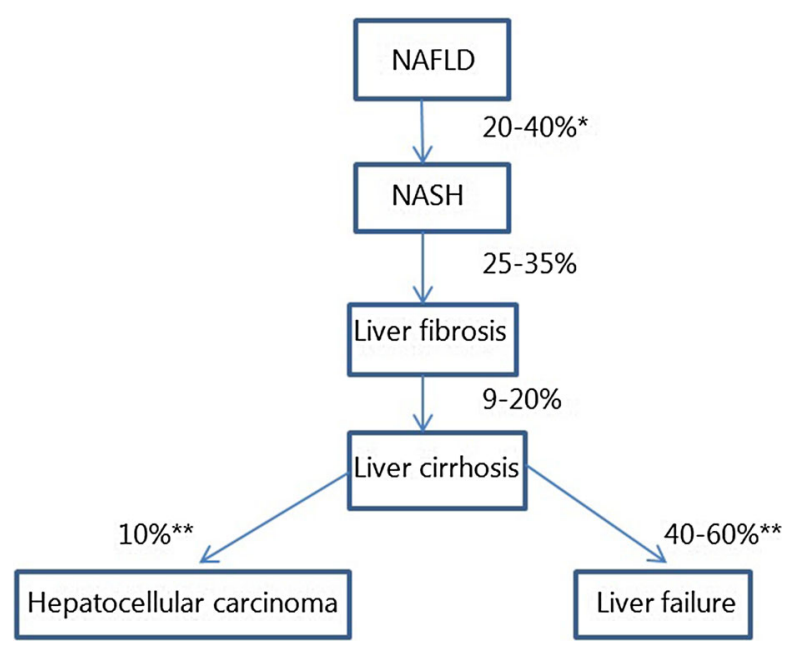

Fig. 1 Schematic representation of the natural history of non-alcoholic fatty liver disease (NAFLD). NASH nonalcoholic steatohepatitis. ${ }^{*}$ In 3-6 years of follow-up ${ }^{* *}$ In 5-7 years of follow-up

liver is increased in the setting of NAFLD. Donnelly et al. showed that hepatic de novo lipogenesis (DNL) accounts for $26.1 \%$ of the hepatic triglyceride formation in NAFLD patients [50]. In contrast, the contribution of DNL in healthy individuals is less than 5\% [51] (Fig. 2). Several studies in animals and humans have shown that both hyperinsulinemia and hyperglycaemia-as markers of IR-stimulate DNL by various pathways, leading to the development of steatosis [52]. The reason why steatosis progresses to NASH is still not fully elucidated. Traditionally, the two-hit theory was widely adopted [53]. In this theory, the 'first hit' is the hepatic accumulation of triglycerides-as a result of an increase in circulating free fatty acids (FFAs). The accumulation increases the susceptibility of the liver for additional hepatotoxic hits. Such an additional factor-'second hit' - eventually leads to local inflammation and NASH. Suggested contributing factors (second hit) include mitochondrial dysfunction, adipose tissue dysfunction and genetic factors. However, some authors state that the 'two-hit' hypothesis is obsolete, as it is inadequate to explain the several molecular and metabolic changes that take place in NAFLD. [47] Therefore, the current literature tends to speak of a 'multiple hit theory' that states that the pathogenesis of NASH is very complex and is the result of multiple hits and not limited to one additional hit in addition to the presence of steatosis. A third theory suggests that the accumulation of triglycerides itself provokes oxidative stress and eventually leads to inflammation and NASH [54].

The human microbiome is increasingly recognized as an important factor in the development of NAFLD/NASH. Suggested mechanisms, like changes in intestinal permeability and production of microbe-derived metabolites, are more extensively addressed in the excellent recent reviews of Leung et al. and Chu et al $[55,56]$. There are no specific studies linking microbiome dysfunction to the development of NASH in HIV-infected patients. Furthermore, there is strong evidence on the impact of hereditary component with polymorphisms for hepatic lipid regulation and insulin signalling pathways, in both the HIV-infected and general populations $[57,58]$.

\section{NAFLD IN HIV-INFECTED PATIENTS}

\section{HIV as Risk Factor for NAFLD}

Although NAFLD is common in HIV-infected patients as a result of traditional risk factors, it is suggested that its exact aetiology may differ from the general population [59]. Interestingly, histopathological studies from the pre-cART era report high numbers of steatosis in treatmentnaïve HIV-infected patients-suggestive of a direct steatotic effect of HIV itself [60, 61]. Furthermore, HIV-infected patients with NAFLD tend to have a lower BMI than HIV-negative controls with NAFLD [62]. These data suggest that HIV-related factors are associated with NAFLD, even in the absence of traditional risk factors such as obesity-related IR. Insulin resistance is highly prevalent-up to $35 \%$-in HIVinfected patients, as a result of ongoing immune activation [63, 64]. This phenomena has also been described in the setting of rheumatoid arthritis in which high levels of pro-inflammatory markers-e.g. TNF alpha and IL-6-were associated with IR [65]. These markers have also been shown to be elevated in chronic HIV- 


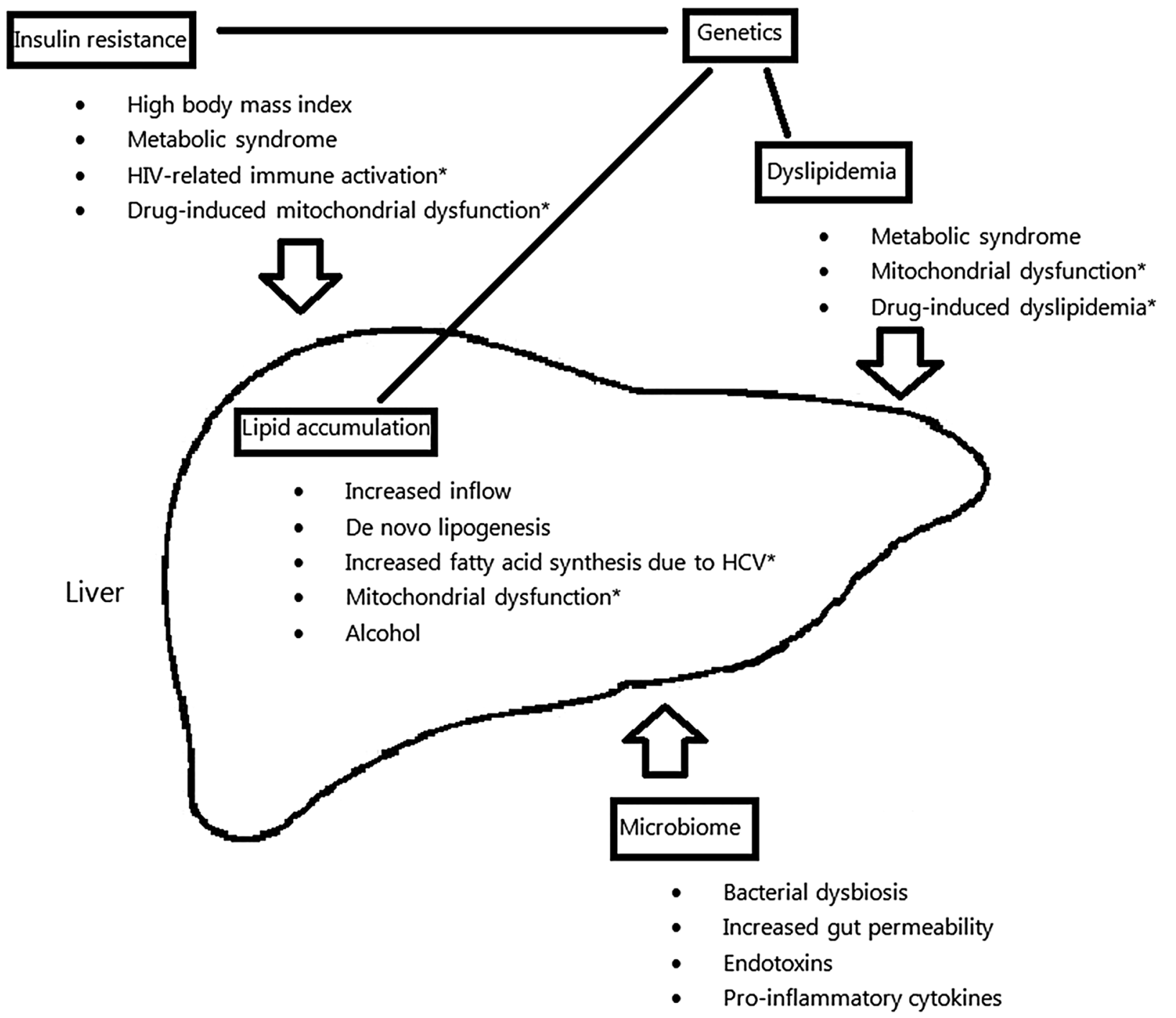

Fig. 2 Schematic representation of the pathogenesis of NAFLD. As shown, there are four major hallmarks in the pathogenesis of NALFD_-insulin resistance, dyslipidemia, hepatic accumulation and the microbiome-with a certain overlap between these factors. As mentioned, genetics play an important role in the overall pathogenesis influencing

infection, but it is unclear to what extent other immune activation markers like sCD14 and the expansion of CD8+/HLA-DR+ subtype T cells contribute to IR in HIV [66]. Most studies on IR in this population describe cART-treated patients, but only one study evaluated the occurrence of IR in treatment-naïve HIV-positive patients [67]. In this heterogeneous most of these factors. The arrows represent a direct impact of a certain hallmark on the development of NAFLD. The contributing factors are mentioned below the hallmarks. Risk factors more common in HIV-infected population are marked with an asterisk

prospective cohort, there was a clear association between advanced HIV-infection-defined as low CD4 counts and detectable viral load-and IR, measured by fasting lipids, glucoses and insulin levels. This and other observations strongly suggest a link between chronic HIVinduced immune activation and IR with subsequent steatosis development [68-70]. 
In contrast to the limited number of studies on glucose haemostasis in HIV-positive patients, several studies have been performed on the occurrence of dyslipidemia-also associated with NAFLD [50]. A study in the early 1990s established that untreated HIV-infected patients with advanced immunodeficiency have higher triglycerides and FFA levels compared to healthy controls [71]. In addition to hypertriglyceridemia, untreated HIV-infected patients have decreased high-density lipoprotein cholesterol and total cholesterol levels. These observations were confirmed in several other studies, although the mechanism of HIV-related dyslipidemia is poorly understood. [72, 73] The study by El-Sadr et al. even established an association between high HIV RNA levels and hypertriglyceridemia [67]. Based on these observations, it seems reasonable to assume that HIV-infection itself plays a role in the development of NAFLD.

\section{Antiretroviral Therapy as a Risk Factor for NAFLD}

As the vast majority of HIV-infected patients treated with cART will reach virological suppression and (near) inhibition of immune activation, the impact of hypertriglyceridemia and IR caused by the virus itself will diminish. In contrast, certain antiretroviral therapy can contribute to the development of NAFLD [74]. cART seems to influence the development of NAFLD in two different ways. First, several antiretroviral drugs cause unfavorable metabolic changes such as dyslipidemia and insulin resistance [75]. Second, the use of certain antiretroviral drugs is associated with mitochondrial dysfunction.

\section{Nucleoside/Nucleotide Reverse Transcriptase Inhibitors (NRTIs)}

Nucleoside/nucleotide reverse transcriptase inhibitors (NRTIs) are still an essential part of current cART regimens. Especially, early-generation NRTIs are associated with insulin resistance and dyslipidemia [76-78]. The main driver for both metabolic disturbances is mitochondrial toxicity. The first reports of mitochondrial dysfunction in NRTIs were published in the early 1990s, but this adverse event gained increasing attention after the introduction of combination therapy [79-81]. NRTI-related metabolic side effects are caused by the inhibition of the replication of mitochondrial DNA (mtDNA) by binding to intra-mitochondrial polymerase gamma. This leads to impairment of the oxidative phosphorylation and promotes the formation of reactive oxygen species which eventually damage the mtDNA even further, resulting in mitochondrial dysfunction [82].

NRTI-related mitochondrial dysfunction contributes to the development of NAFLD in several ways. First, both IR and dyslipidemia can be the result of mitochondrial dysfunction in the peripheral fat tissue [83]. Even though the mechanism is not exactly clear, mitochondrial dysfunction seems to induce adipocyte apoptosis, leading to peripheral lipodystrophy. The clinical syndrome is characterized by the degeneration of peripheral fat tissue combined with metabolic changes such as IR and dyslipidemia [81, 84]. In addition to peripheral effects, mitochondrial dysfunction also occurs in the liver. Hepatic mitochondria play an essential role in the oxidation of FFAs. In the setting of mitochondrial dysfunction, mitochondria are unable to process this oxidation, leading to a local accumulation of triglycerides which is the hallmark of NAFLD [85]. Early-generation NRTIs are most commonly associated with mitochondrial dysfunction; especially stavudine, didanosine, zalcitabine and-to a lesser extentzidovudine [86]. Modern NRTIs-e.g. tenofovir, abacavir, lamivudine and emtricitabine-are rarely implicated in clinically significant mitochondrial dysfunction and are less likely to contribute to NAFLD development in this way [87].

\section{Protease Inhibitors (PIs)}

Introduction of protease inhibitors (PIs) in 1995 broadened the possibilities in the treatment of HIV infection. However, PIs display an 
unfavorable metabolic profile with an increased risk for insulin resistance and dyslipidemia.

Especially, the early-generation PIs-e.g. indinavir and therapeutic-dosed ritonavirwere known for their ability to induce IR [88]. Two animal studies showed that these PIs act as potent isoform-specific inhibitors of the transport function of the GLUT4-receptor, resulting in hyperglycemia and hyperinsulinemia $[89,90]$. Additional data suggested the ability to directly inhibit insulin secretion from the beta cells [91, 92]. In contrast to early-generation PIs, current PIs like atazanavir and darunavir display a far more favorable profile with regard to IR [93]. Although the newer generation PIs seem to have little impact on the lipid levels in monotherapy, when combined with ritonavir or cobicistat as a pharmacological booster, these drugs still have an unfavorable lipid profile compared to most other classes of antiretroviral drugs [94-97]. The exact mechanism of PI-induced dyslipidaemia remains the subject of debate. Data suggest that PIs attribute to an increase of ApolipoproteinB which transports LDL- and VLDL-cholesterol and triglycerides in the circulation [98]. Secondly, experimental research in mice showed that ritonavir inhibits the clearance of triglycerides from the circulation [99].

\section{Non-Nucleoside Reverse Transcriptase Inhibitors (NNRTIs)}

The amount of data describing the metabolic profile of the non-nucleoside reverse transcriptase inhibitors (NNRTIs) is limited compared to the number of studies for PI-based treatment. Rilpivirine and nevirapine have a more favorable profile compared to efavirenz [100, 101]. Etravirine does not seem to influence lipid levels when compared with placebo [102]. Recently, the new NNRTI Doravirine was approved by the FDA; in the DRIVE-AHEAD and DRIVE-FORWARD trials, this novel drug showed lower triglyceride and LDL levels when compared to Efavirenz and Darunavir $[103,104]$.

\section{Integrase Strand Transfer Inhibitors (INSTI)}

In 2008, the first integrase strand transfer inhibitor (INSTI), raltegravir, was introduced. This new drug class is generally considered advantageous in respect with the metabolic profile. $[105,106]$ The lipid profile of the recently approved bictegravir is comparable to dolutegravir. [107, 108].

\section{Other Antiretroviral Classes}

Data on entry-inhibitors (e.g. maraviroc and enfuviritide) are limited, but no negative effects have so far been reported $[109,110]$. None of these agents are implicated in the development of NAFLD.

\section{Non-HIV or -cART-Related Risk Factors for NAFLD}

In addition to the risk factors that are directly linked to HIV-infection and cART, HIV-infected patients are exposed to other risk factors for the development of NAFLD. First of all, a significant proportion of the population is suffering from a hepatitis C virus (HCV)/HIV co-infection [111]. $\mathrm{HCV}$ genotype 3 has been identified as an independent risk factor for the development of NAFLD [112]. The current literature suggests that these specific genotype 3 antigens induce upregulation of hepatic fatty acid synthesis $[113,114]$. When HCV genotype 3-infected patients achieve sustained viral response (i.e. cure) after treatment, the degree of steatosis diminishes [115]. In contrast to HCV genotype 3 infection, the current literature suggests that hepatitis B virus is associated with a lower risk for NAFLD [116]. However, the most important non-HIV/non-cART risk factors are probably the previously mentioned 'traditional' risk factors such as obesity-related IR and diabetes mellitus. Nowadays, HIV-patients grow old enough to be exposed to these traditional risk factors. Recent publications describe increases in median bodymass index (BMI) and the incidence of diabetes mellitus in the HIV-infected population, adding more risks for this population [14, 117, 118]. 
The impact of traditional risk factors was emphasized by the results of the meta-analysis of Maurice et al., identifying high BMI, waist circumference, type 2 diabetes, hypertension and high triglycerides as the significant risk factors for NAFLD [19].

\section{TREATMENT}

\section{Lifestyle Modification}

Despite extensive research over recent years, treatment of NAFLD remains challenging. Weight loss is still the most important intervention in all patients $[119,120]$. A sustained weight loss of approximately $10 \%$ is needed to improve the majority of the histopathological features of NASH [121]. Furthermore, excessive use of alcohol is discommended as alcohol itself can cause significant liver disease. Although the AASLD guideline recommends that patients with NAFLD should not consume heavy amounts of alcohol-4 standard drinks a day or $>14$ per week for men and 3 standard drinks per day or 7 per week for women-it states that there are insufficient data to make recommendations with regard to non-heavy alcohol consumption [44]. In the setting of NASH, alcohol consumption is the most significant factor associated with the risk of HCC [122]. For this population, total abstinence is mandatory according to the European Association for Study of the Liver (EASL) [123].

\section{Medical Treatment}

Next to behavioural interventions, several medical treatments have been described to be effective [44]. The most recent AASLD guideline supports the use of pioglitazone and vitamin $\mathrm{E}$ in biopsy-proven NASH. These recommendations are mainly based on the study of Sanyal et al. describing a trial comparing three groups-pioglitazone (30 mg daily) or vitamin E (800 IE daily) or placebo-in patients with biopsy-proven NASH [124]. Patients were randomized and treated for 96 weeks; all patients underwent follow-up liver biopsy. The primary outcome was an improvement in histological features of NASH as a composite endpoint of standardized scores of steatosis, lobular inflammation, hepatocellular ballooning, and fibrosis. Vitamin E therapy versus placebo showed a significantly higher rate of improvement in biopsy-proven NASH $(43 \%$ vs. $19 \% P=0.001)$. However, the use of vitamin $\mathrm{E}$ is not strongly advocated since the SELECT trial from 2011 suggested an increased risk for prostate cancer in patients receiving $400 \mathrm{mg}$ vitamin $\mathrm{E}$ daily with a hazard ratio of 1.16 (99\% CI 1.004-1.36, $P=0.008)$ compared to placebo. In the trial of Sanyal et al., the use of pioglitazone also seems to improve the histological features of NASH, although statistical significance was not reached $-34 \%$ of the pioglitazone group versus $19 \%$ of placebo showed improvement $(P=0.04)$. A major side effect of pioglitazone was weight gain [125]. Furthermore, its use seems to be associated with the development of bladder cancer, although data are conflicting $[126,127]$. The EASL guideline recommends that an insulin sensitizer can be used, in particular in patients with type II diabetes mellitus (T2DM) [123]. The AASLD suggests its use in biopsy-proven NASH regardless of T2DM status [44]. Both the EASL and AASLD suggest considering vitamin $\mathrm{E}$ only in non-diabetic noncirrhotic adults with biopsy-proven NASH. Other medical interventions, such as metformin, glucagon-like peptide-1 (GLP-1) agonists and ursodeoxycholic acid are suggested as alternatives, but have not been proven effective and are therefore not recommended in current guidelines.

\section{Bariatric Surgery}

Bariatric surgery is another treatment option that has increasingly been recognized as a potential intervention for NAFLD [128]. Several studies established high rates of histological improvement in NASH in patients with significant weight loss after bariatric surgery $[120,129]$. The AASLD guideline recommends that bariatric surgery can be considered in otherwise eligible obese individuals with NAFLD, but it is premature to consider surgery 
to specifically treat NAFLD [44]. With respect to HIV-infected patients, interventions should be guided by the specific pathophysiological aspects regarding HIV- and cART-related NAFLD in addition to standard care. First of all, these interventions should focus on reducing the degree of immune activation in HIV infection by early introduction of effective antiretroviral therapy, aiming to reach full virological suppression and optimal immunological recovery. After publication of the START Study, current HIV treatment guidelines recommend the start of antiretroviral therapy regardless of the $\mathrm{CD} 4^{+}$ cell count $[130,131]$. As a result of this early initiation of cART, the time of immune activation is limited and the degree of IR will decrease-as one of the most important factors of HIV-related NAFLD. Several studies showed that, even in the setting of virological suppression, there is some residual immune activation [132-134]. However, the impact of the lowgrade immune activation on the development of insulin resistance and NAFLD is currently unclear. Second, if patients are using a cART regimen with an unfavourable metabolic profile-like protease inhibitors or early-generation NRTIs-changes in cART should be considered. Although current guidelines prefer the use of INSTI-based over PI-based regimens, and modern PIs display a more favourable metabolic profile, some patients are still at risk for NAFLD as a result of cART-related dyslipidaemia.

\section{FUTURE EXPECTATIONS}

\section{Epidemiology}

In the upcoming years, the epidemiology and management of NAFLD is expected to change. As a result of an increased life expectancy and the number of years living in good health, risk factors for the general population are increasingly applicable for the HIV-infected population. In their 2010 paper, Crum-Cianflone et al. demonstrated significant increases in weight in HIV-infected patients over the years [135]. Among those diagnosed in the cART era, nearly two-thirds of the population were overweight or obese at last visit. This percentage is similar to the United States of America general population, confirming the observation that HIV-infected patients increasingly resemble the general population in respect of risk factors for NAFLD. Therefore, the upcoming years will be characterised by the transition from the HIVand cART-related risk factors towards the 'classical' risk factors for the development of NAFLD. During this transitional period, HIV-treating physicians should be aware of the high prevalence of NAFLD in their patient population, especially for those who were diagnosed in the pre- and early-cART eras, those with low nadir CD4 counts and those who received early-generation antiretroviral therapy. Furthermore, it should not be forgotten that NAFLD can be the first utterance of underlying cardiovascular disease. Its finding may require other diagnostic or therapeutic interventions.

\section{Treatment}

In addition to changes in epidemiology and diagnostics, several drugs are currently under investigation which can be divided in non-antifibrotic and antifibrotic drugs [136]. Current phase 3 studies for the non-antifibrotic drugs focus on the regulation of triglycerides and diminishing IR. These include farnesoid $X$ receptor and peroxisome proliferator-activated alpha/delta (PPAR $\alpha / \delta$ ) receptor agonists. For example, PPAR $\alpha / \delta$ receptors are present in adipose tissue, muscles and the liver among other tissues, and stimulation promotes mitochondrial beta oxidation and diminishes IR by various pathways [137]. Elafibranor is a PPAR $\alpha / \delta$ agonist which is currently being tested in a phase 3 clinical trial. An earlier study using follow-up liver biopsies suggested significantly more resolution of NASH without fibrosis worsening in patients receiving elafibranor versus placebo $[19 \%$ vs. $12 \%, O R=2.31(95 \%$ CI.02-5.24 $(P=0.045)]$ [138]. With respect to the antifibrotic drugs, selonsertib is currently being investigated in a phase 3 clinical trial [139]. Selonsertib is an inhibitor of apoptosis signal-regulating kinase 1 , a serine/threonine signalling kinase that induces hepatic inflammation, apoptosis and fibrosis in the setting of 
oxidative stress [140]. In an animal model, selonsertib seemed effective in diminishing hepatic inflammation and fibrosis [141]. A phase 2 study evaluated the efficacy of selonsertib; patients were randomized into five groups: selonsertib monotherapy (18 $\mathrm{mg}$ or $6 \mathrm{mg}$ ) versus selonsertib (18 $\mathrm{mg}$ or $6 \mathrm{mg}$ ) plus simtuzumab (another antifibrotic drug) versus simtuzumab monotherapy in patients with biopsy-proven NASH [142]. As another study in the meantime established that simtuzumab was ineffective, the selonsertib groups with and without simtuzumab were pooled per dosage [143]. Reduction of one or more stages in biopsy-proven fibrosis was observed in $43 \%$ of patients treated with $18 \mathrm{mg}$ selonsertib, 30\% among those treated with $6 \mathrm{mg}$ selonsertib and $20 \%$ in those treated with simtuzumab monotherapy-suggesting beneficial effects of selonsertib. Further studies will follow in the near future.

With respect to HIV-infected patients, few specific trials have been or are being performed. To the best of our knowledge, only two studies focussing on NAFLD in HIV-infected patients are currently active. Recently, the ARRIVE Trial was completed with the results pending. In this study, HIV-infected patients with documented NAFLD were randomized to aramachol versus placebo. The effect on steatosis will be evaluated using MRI-imaging [144]. Aramchol is a synthetic fatty-acid/bile-acid conjugate that inhibits the synthesis of fatty acids, which appeared to be safe and effective in an earlier trial [145]. A second trial is currently evaluating the effects of tesamorelin-a growth-hormone-releasing hormone (GHRH) analogue-on the degree of steatosis, with the endpoint measured by MRSPDFF [146]. Two earlier studies in HIV-infected patients suggested beneficial effects when comparing tesamorelin versus placebo $[147,148]$. One study determined that the amount of liver fat diminished-assessed by MRS-as result of GHRH analogue treatment, while the other report found that the use of tesamorelin significantly reduced liver enzyme values compared to placebo. It is not completely clear how GHRH augmentation alters the hepatic fat storage, but it is suggested that it inhibits de novo lipogenesis in the liver [149].
In conclusion, although the life expectancy of HIV-infected patients has increased dramatically after the introduction of cART, liver-related morbidity continues to be a great burden in this population. In some patients, residual inflammation persists, certain antiretroviral drugs continue to influence the metabolic profile and HIV-infected patients will grow old enough to face the traditional risk factors for NAFLD. These developments should make us aware of the high risk of NAFLD in this population and warrant further research on modification of both the traditional and HIV-related risk factors and therapeutic interventions.

\section{ACKNOWLEDGEMENTS}

Funding. No funding or sponsorship was received for this study or publication of this article.

Authorship. All named authors meet the International Committee of Medical Journal Editors (ICMJE) criteria for authorship for this article, take responsibility for the integrity of the work as a whole, and have given their approval for this version to be published.

Disclosures. Berend J. van Welzen, Ayman El Idrissi and Tania Mudrikova have nothing to disclose. Andy I.M. Hoepelman: Advisory boards fees from Abbvie, BMS, Gilead, Janssen, MSD. Consultancy: AbbVie. Joop E. Arends: Advisory board fees from Gilead, MSD, Janssen, ViiV, Abbvie and BMS. (Research) grants from MSD, Abbvie, ViiV and BMS (money is paid to the institution).

Compliance with Ethics Guidelines. This article is based on previously conducted studies and does not contain any studies with human participants or animals performed by any of the authors.

Data Availability. Data sharing is not applicable to this article as no datasets were generated or analyzed during the current study. 
Open Access. This article is distributed under the terms of the Creative Commons Attribution-NonCommercial 4.0 International License (http://creativecommons.org/licenses/ by-nc/4.0/), which permits any noncommercial use, distribution, and reproduction in any medium, provided you give appropriate credit to the original author(s) and the source, provide a link to the Creative Commons license, and indicate if changes were made.

\section{REFERENCES}

1. Maartens G, Celum C, Lewin SR. HIV infection: epidemiology, pathogenesis, treatment, and prevention. Lancet. 2014;384:258-71.

2. Price JC, Thio CL. Liver disease in the HIV-infected individual. Clin Gastroenterol Hepatol. 2010;8:1002-12.

3. Alter MJ. Epidemiology of viral hepatitis and HIV co-infection. J Hepatol. 2006;44:S6-9.

4. Galvan FH, Bing EG, Fleishman JA, London AS, Caetano R, Burnam MA, et al. The prevalence of alcohol consumption and heavy drinking among people with HIV in the United States: results from the HIV Cost and Services Utilization Study. J Stud Alcohol. 2002;63:179-86.

5. Caldwell SH, Crespo DM. The spectrum expanded: cryptogenic cirrhosis and the natural history of non-alcoholic fatty liver disease. J Hepatol. 2004;40:578-84.

6. Tsochatzis EA, Bosch J, Burroughs AK. Liver cirrhosis. Lancet. 2014;383:1749-61.

7. Kleiner DE, Makhlouf HR. Histology of nonalcoholic fatty liver disease and nonalcoholic steatohepatitis in adults and children. Clin Liver Dis. 2016;20:293-312.

8. Aboud M, Elgalib A, Kulasegaram R, Peters B. Insulin resistance and HIV infection: a review. Int J Clin Pract. 2007;61:463-72.

9. Araujo S, Banon S, Machuca I, Moreno A, Perez-Elias MJ, Casado JL. Prevalence of insulin resistance and risk of diabetes mellitus in HIV-infected patients receiving current antiretroviral drugs. Eur J Endocrinol. 2014;171:545-54.

10. Blas-Garcia A, Apostolova N, Esplugues JV. Oxidative stress and mitochondrial impairment after treatment with anti-HIV drugs: clinical implications. Curr Pharm Des. 2011;17:4076-86.

11. Yoon EJ, Hu K-Q. Hepatitis C virus (HCV) infection and hepatic steatosis. Int J Med Sci. 2006;3:53-6.

12. Younossi ZM, Koenig AB, Abdelatif D, Fazel Y, Henry L, Wymer M. Global epidemiology of nonalcoholic fatty liver disease-meta-analytic assessment of prevalence, incidence, and outcomes. Hepatology. 2016;64:73-84.

13. Macias J, Gonzalez J, Tural C, Ortega-Gonzalez E, Pulido F, Rubio R, et al. Prevalence and factors associated with liver steatosis as measured by transient elastography with controlled attenuation parameter in HIV-infected patients. AIDS. 2014;28:1279-87.

14. Crum-Cianflone N, Dilay A, Collins G, Asher D, Campin R, Medina S, et al. Nonalcoholic fatty liver disease among HIV-infected persons. J Acquir Immune Defic Syndr. 2009;50:464-73.

15. Guaraldi G, Squillace N, Stentarelli C, Orlando G, $D^{\prime}$ Amico $R$, Ligabue $G$, et al. Nonalcoholic fatty liver disease in HIV-infected patients referred to a metabolic clinic: prevalence, characteristics, and predictors. Clin Infect Dis. 2008;47:250-7.

16. Lui G, Wong VW-S, Wong GL-H, Chu WC-W, Wong C-K, Yung IMH, et al. Liver fibrosis and fatty liver in Asian HIV-infected patients. Aliment Pharmacol Ther. 2016;44:411-21.

17. Nishijima T, Gatanaga $H$, Shimbo T, Komatsu H, Nozaki Y, Nagata N, et al. Traditional but not HIVrelated factors are associated with nonalcoholic fatty liver disease in Asian patients with HIV-1 infection. PLoS ONE. 2014;9:e87596.

18. Vuille-Lessard E, Lebouche B, Lennox L, Routy J-P, Costiniuk CT, Pexos C, et al. Nonalcoholic fatty liver disease diagnosed by transient elastography with controlled attenuation parameter in unselected HIV monoinfected patients. AIDS. 2016;30:2635-43.

19. Maurice JB, Patel A, Scott AJ, Patel K, Thursz M, Lemoine M. Prevalence and risk factors of nonalcoholic fatty liver disease in HIV-monoinfection. AIDS. 2017;31:1621-32.

20. Ingiliz $P$, Valantin M-A, Duvivier C, Medja F, Dominguez $S$, Charlotte $F$, et al. Liver damage underlying unexplained transaminase elevation in human immunodeficiency virus-1 mono-infected patients on antiretroviral therapy. Hepatology. 2009;49:436-42.

21. Morse CG, McLaughlin M, Matthews L, Proschan M, Thomas F, Gharib AM, et al. Nonalcoholic 
steatohepatitis and hepatic fibrosis in HIV-1monoinfected adults with elevated aminotransferase levels on antiretroviral therapy. Clin Infect Dis. 2015;60:1569-78.

22. Sterling RK, Smith PG, Brunt EM. Hepatic steatosis in human immunodeficiency virus: a prospective study in patients without viral hepatitis, diabetes, or alcohol abuse. J Clin Gastroenterol. 2013;47:182-7.

23. Lemoine M, Barbu V, Girard PM, Kim M, Bastard J-P, Wendum D, et al. Altered hepatic expression of SREBP-1 and PPARgamma is associated with liver injury in insulin-resistant lipodystrophic HIV-infected patients. AIDS. 2006;20:387-95.

24. Lombardi R, Lever R, Smith C, Marshall N, Rodger $\mathrm{A}$, Bhagani $\mathrm{S}$, et al. Liver test abnormalities in patients with HIV mono-infection: assessment with simple noninvasive fibrosis markers. Ann Gastroenterol. 2017;30:349-56.

25. Price JC, Seaberg EC, Latanich R, Budoff MJ, Kingsley LA, Palella FJJ, et al. Risk factors for fatty liver in the multicenter AIDS cohort study. Am J Gastroenterol. 2014;109:695-704.

26. Kardashian A, Ma Y, Scherzer R, Price JC, Sarkar M, Korn N, et al. Sex differences in the association of HIV infection with hepatic steatosis. AIDS. 2017;31:365-73.

27. Chalasani N, Younossi Z, Lavine JE, Diehl AM, Brunt EM, Cusi $K$, et al. The diagnosis and management of non-alcoholic fatty liver disease: practice Guideline by the American Association for the Study of Liver Diseases, American College of Gastroenterology, and the American Gastroenterological Association. Hepatology. 2012;55:2005-23.

28. Bravo AA, Sheth SG, Chopra S. Liver biopsy. N Engl J Med. 2001;344:495-500.

29. Stern C, Castera L. Non-invasive diagnosis of hepatic steatosis. Hepatol Int. 2017;11:70-8.

30. Khov N, Sharma A, Riley TR. Bedside ultrasound in the diagnosis of nonalcoholic fatty liver disease. World J Gastroenterol. 2014;20:6821-5.

31. Lee SS, Park SH. Radiologic evaluation of nonalcoholic fatty liver disease. World J Gastroenterol. 2014;20:7392-402.

32. Caussy C, Reeder SB, Sirlin CB, Loomba R. Noninvasive, quantitative assessment of liver fat by MRIPDFF as an endpoint in NASH trials. Hepatology. 2018;68:763-72.

33. Sasso M, Beaugrand M, de Ledinghen V, Douvin C, Marcellin P, Poupon R, et al. Controlled attenuation parameter (CAP): a novel VCTE guided ultrasonic attenuation measurement for the evaluation of hepatic steatosis: preliminary study and validation in a cohort of patients with chronic liver disease from various causes. Ultrasound Med Biol. 2010;36:1825-35.

34. Wang Y, Fan Q, Wang T, Wen J, Wang H, Zhang T. Controlled attenuation parameter for assessment of hepatic steatosis grades: a diagnostic meta-analysis. Int J Clin Exp Med. 2015;8:17654-63.

35. Ajmera V, Loomba R. Can elastography differentiate isolated fatty liver from nonalcoholic steatohepatitis? Semin Liver Dis. 2018;38:14-20.

36. Ong JP, Younossi ZM. Epidemiology and natural history of NAFLD and NASH. Clin Liver Dis. 2007;11(1-16):vii.

37. Farrell GC, Larter CZ. Nonalcoholic fatty liver disease: from steatosis to cirrhosis. Hepatology. 2006;43:S99-112.

38. Verma S, Jensen D, Hart J, Mohanty SR. Predictive value of ALT levels for non-alcoholic steatohepatitis (NASH) and advanced fibrosis in non-alcoholic fatty liver disease (NAFLD). Liver Int. 2013;33:1398-405.

39. Sorrentino P, Tarantino G, Conca P, Perrella A, Terracciano ML, Vecchione R, et al. Silent non-alcoholic fatty liver disease-a clinical-histological study. J Hepatol. 2004;41:751-7.

40. Ruhl CE, Everhart JE. Upper limits of normal for alanine aminotransferase activity in the United States population. Hepatology. 2012;55:447-54.

41. Angulo P, Hui JM, Marchesini G, Bugianesi E, George J, Farrell GC, et al. The NAFLD fibrosis score: a noninvasive system that identifies liver fibrosis in patients with NAFLD. Hepatology. 2007;45:846-54.

42. Ryom L, Boesecke C, Bracchi M, Ambrosioni J, Pozniak A, Arribas J, et al. Highlights of the 2017 European AIDS Clinical Society (EACS) Guidelines for the treatment of adult HIV-positive persons version 9.0. HIV Med. 2018;19:309-15.

43. Brunt EM, Tiniakos DG. Histopathology of nonalcoholic fatty liver disease. World J Gastroenterol. 2010;16:5286-96.

44. Chalasani N, Younossi Z, Lavine JE, Charlton M, Cusi K, Rinella M, et al. The diagnosis and management of nonalcoholic fatty liver disease: practice guidance from the American Association for the Study of Liver Diseases. Hepatology. 2018;67:328-57.

45. Mellinger JL, Pencina KM, Massaro JM, Hoffmann U, Seshadri S, Fox CS, et al. Hepatic steatosis and cardiovascular disease outcomes: an analysis of the 
Framingham Heart Study. J Hepatol. 2015;63:470-6.

46. Crum-Cianflone N, Krause D, Wessman D, Medina $\mathrm{S}$, Stepenosky J, Brandt C, et al. Fatty liver disease is associated with underlying cardiovascular disease in HIV-infected persons $\left({ }^{*}\right)$. HIV Med. 2011;12:463-71.

47. Buzzetti E, Pinzani M, Tsochatzis EA. The multiplehit pathogenesis of non-alcoholic fatty liver disease (NAFLD). Metabolism. 2016;65:1038-48.

48. Fruhbeck G, Mendez-Gimenez L, Fernandez-Formoso J-A, Fernandez S, Rodriguez A. Regulation of adipocyte lipolysis. Nutr Res Rev. 2014;27:63-93.

49. Xia B, Cai GH, Yang H, Wang SP, Mitchell GA, Wu JW. Adipose tissue deficiency of hormone-sensitive lipase causes fatty liver in mice. PLoS Genet. 2017;13:e1007110.

50. Donnelly KL, Smith CI, Schwarzenberg SJ, Jessurun J, Boldt MD, Parks EJ. Sources of fatty acids stored in liver and secreted via lipoproteins in patients with nonalcoholic fatty liver disease. J Clin Invest. 2005;115:1343-51.

51. Parks EJ. Dietary carbohydrate's effects on lipogenesis and the relationship of lipogenesis to blood insulin and glucose concentrations. $\mathrm{Br} \mathrm{J}$ Nutr. 2002;87(Suppl 2):S247-53.

52. Samuel VT, Shulman GI. Mechanisms for insulin resistance: common threads and missing links. Cell. 2012;148:852-71.

53. Day CP, James OF. Steatohepatitis: a tale of two "hits"? Gastroenterology. 1998;114:842-5.

54. Feldstein AE, Werneburg NW, Canbay A, Guicciardi ME, Bronk SF, Rydzewski R, et al. Free fatty acids promote hepatic lipotoxicity by stimulating TNFalpha expression via a lysosomal pathway. Hepatology. 2004;40:185-94.

55. Chu H, Duan Y, Yang L, Schnabl B. Small metabolites, possible big changes: a microbiota-centered view of non-alcoholic fatty liver disease. Gut Published Online First. 2018. https://doi.org/10.1136/ gutjnl-2018-316307.

56. Leung C, Rivera L, Furness JB, Angus PW. The role of the gut microbiota in NAFLD. Nat Rev Gastroenterol Hepatol. 2016;13:412-25.

57. Eslam M, Valenti L, Romeo S. Genetics and epigenetics of NAFLD and NASH: Clinical impact. J Hepatol. 2018;68:268-79.

58. Macias J, Rivero-Juarez A, Neukam K, Tellez F, Merino D, Frias M, et al. Impact of genetic polymorphisms associated with nonalcoholic fatty liver disease on HIV-infected individuals. AIDS. 2015;29:1927-35.

59. Vodkin I, Valasek MA, Bettencourt R, Cachay E, Loomba R. Clinical, biochemical and histological differences between HIV-associated NAFLD and primary NAFLD: a case-control study. Aliment Pharmacol Ther. 2015;41:368-78.

60. Lebovics E, Thung SN, Schaffner F, Radensky PW. The liver in the acquired immunodeficiency syndrome: a clinical and histologic study. Hepatology. 1985;5:293-8.

61. Glasgow BJ, Anders K, Layfield LJ, Steinsapir KD, Gitnick GL, Lewin KJ. Clinical and pathologic findings of the liver in the acquired immune deficiency syndrome (AIDS). Am J Clin Pathol. 1985;83:582-8.

62. Mohammed SS, Aghdassi E, Salit IE, Avand G, Sherman M, Guindi M, et al. HIV-positive patients with nonalcoholic fatty liver disease have a lower body mass index and are more physically active than HIV-negative patients. J Acquir Immune Defic Syndr. 2007;45:432-8.

63. Gutierrez AD, Balasubramanyam A. Dysregulation of glucose metabolism in HIV patients: epidemiology, mechanisms, and management. Endocrine. 2012;41:1-10.

64. Limone P, Biglino A, Valle M, Degioanni M, Paola Servato $M$, Berardi $C$, et al. Insulin resistance in HIV-infected patients: relationship with pro-inflammatory cytokines released by peripheral leukocytes. J Infect. 2003;47:52-8.

65. Nicolau J, Lequerre $T$, Bacquet $H$, Vittecoq $O$. Rheumatoid arthritis, insulin resistance, and diabetes. Joint Bone Spine. 2017;84:411-6.

66. Nou E, Lo J, Grinspoon SK. Inflammation, immune activation, and cardiovascular disease in HIV. AIDS. 2016;30:1495-509.

67. El-Sadr WM, Mullin CM, Carr A, Gibert C, Rappoport C, Visnegarwala F, et al. Effects of HIV disease on lipid, glucose and insulin levels: results from a large antiretroviral-naive cohort. HIV Med. 2005;6:114-21.

68. Hotamisligil GS. Inflammation and metabolic disorders. Nature. 2006;444:860-7.

69. Duncan BB, Schmidt MI, Pankow JS, Ballantyne CM, Couper D, Vigo A, et al. Low-grade systemic inflammation and the development of type 2 diabetes: the atherosclerosis risk in communities study. Diabetes. 2003;52:1799-805. 
70. Armah KA, McGinnis K, Baker J, Gibert C, Butt AA, Bryant $\mathrm{KJ}$, et al. HIV status, burden of comorbid disease, and biomarkers of inflammation, altered coagulation, and monocyte activation. Clin Infect Dis. 2012;55:126-36.

71. Grunfeld C, Pang M, Doerrler W, Shigenaga JK, Jensen P, Feingold KR. Lipids, lipoproteins, triglyceride clearance, and cytokines in human immunodeficiency virus infection and the acquired immunodeficiency syndrome. J Clin Endocrinol Metab. 1992;74:1045-52.

72. Constans J, Pellegrin JL, Peuchant E, Dumon MF, Pellegrin I, Sergeant C, et al. Plasma lipids in HIVinfected patients: a prospective study in 95 patients. Eur J Clin Invest. 1994;24:416-20.

73. Zangerle R, Sarcletti M, Gallati H, Reibnegger G, Wachter H, Fuchs D. Decreased plasma concentrations of HDL cholesterol in HIV-infected individuals are associated with immune activation. J Acquir Immune Defic Syndr. 1994;7:1149-56.

74. da Cunha J, Maselli LMF, Stern ACB, Spada C, Bydlowski SP. Impact of antiretroviral therapy on lipid metabolism of human immunodeficiency virus-infected patients: old and new drugs. World J Virol. 2015;4:56-77.

75. Dekkers CC, Westerink J, Hoepelman AIM, Arends JE. Overcoming obstacles in lipid-lowering therapy in patients with HIV-a systematic review of current evidence. AIDS Rev. 2018;20:205-19.

76. Brown TT, Li X, Cole SR, Kingsley LA, Palella FJ, Riddler SA, et al. Cumulative exposure to nucleoside analogue reverse transcriptase inhibitors is associated with insulin resistance markers in the Multicenter AIDS Cohort Study. AIDS. 2005;19:1375-83.

77. Gallant JE, Staszewski S, Pozniak AL, DeJesus E, Suleiman JMAH, Miller MD, et al. Efficacy and safety of tenofovir DF vs stavudine in combination therapy in antiretroviral-naive patients: a 3-year randomized trial. JAMA. 2004;292:191-201.

78. Crane HM, Grunfeld C, Willig JH, Mugavero MJ, Van Rompaey S, Moore R, et al. Impact of NRTIs on lipid levels among a large HIV-infected cohort initiating antiretroviral therapy in clinical care. AIDS. 2011;25:185-95.

79. Dalakas MC, Illa I, Pezeshkpour GH, Laukaitis JP, Cohen B, Griffin JL. Mitochondrial myopathy caused by long-term zidovudine therapy. N Engl J Med. 1990;322:1098-105.

80. White AJ. Mitochondrial toxicity and HIV therapy. Sex Transm Infect. 2001;77:158-73.
81. Brinkman K, Smeitink JA, Romijn JA, Reiss P. Mitochondrial toxicity induced by nucleoside-analogue reverse-transcriptase inhibitors is a key factor in the pathogenesis of antiretroviral-therapy-related lipodystrophy. Lancet. 1999;354:1112-5.

82. Gardner K, Hall PA, Chinnery PF, Payne BAI. HIV treatment and associated mitochondrial pathology: review of 25 years of in vitro, animal, and human studies. Toxicol Pathol. 2014;42:811-22.

83. Kakuda TN, Brundage RC, Anderson PL, Fletcher CV. Nucleoside reverse transcriptase inhibitor-induced mitochondrial toxicity as an etiology for lipodystrophy. AIDS. 1999;13:2311-2.

84. Baril J-G, Junod P, Leblanc R, Dion H, Therrien R, Laplante F, et al. HIV-associated lipodystrophy syndrome: a review of clinical aspects. Can J Infect Dis Med Microbiol. 2005;16:233-43.

85. Wei Y, Rector RS, Thyfault JP, Ibdah JA. Nonalcoholic fatty liver disease and mitochondrial dysfunction. World J Gastroenterol. 2008;14:193-9.

86. Johnson AA, Ray AS, Hanes J, Suo Z, Colacino JM, Anderson KS, et al. Toxicity of antiviral nucleoside analogs and the human mitochondrial DNA polymerase. J Biol Chem. 2001;276:40847-57.

87. Birkus G, Hitchcock MJM, Cihlar T. Assessment of mitochondrial toxicity in human cells treated with tenofovir: comparison with other nucleoside reverse transcriptase inhibitors. Antimicrob Agents Chemother. 2002;46:716-23.

88. Lee GA, Rao M, Mulligan K, Lo JC, Aweeka F, Schwarz J-M, et al. Effects of ritonavir and amprenavir on insulin sensitivity in healthy volunteers. AIDS. 2007;21:2183-90.

89. Murata H, Hruz PW, Mueckler M. The mechanism of insulin resistance caused by HIV protease inhibitor therapy. J Biol Chem. 2000;275:20251-4.

90. Vyas AK, Koster JC, Tzekov A, Hruz PW. Effects of the HIV protease inhibitor ritonavir on GLUT4 knock-out mice. J Biol Chem. 2010;285:36395-400.

91. Schutt M, Zhou J, Meier M, Klein HH. Long-term effects of HIV-1 protease inhibitors on insulin secretion and insulin signaling in INS-1 beta cells. J Endocrinol. 2004;183:445-54.

92. Behrens G, Dejam A, Schmidt H, Balks HJ, Brabant $\mathrm{G}$, Korner T, et al. Impaired glucose tolerance, beta cell function and lipid metabolism in HIV patients under treatment with protease inhibitors. AIDS. 1999; 13:F63-70.

93. Busti AJ, Bedimo R, Margolis DM, Hardin DS. Improvement in insulin sensitivity and 
dyslipidemia in protease inhibitor-treated adult male patients after switch to atazanavir/ritonavir. J Investig Med. 2008;56:539-44.

94. Hui DY. Effects of HIV protease inhibitor therapy on lipid metabolism. Prog Lipid Res. 2003;42:81-92.

95. Cahn PE, Gatell JM, Squires K, Percival LD, Piliero PJ, Sanne IA, et al. Atazanavir-a once-daily HIV protease inhibitor that does not cause dyslipidemia in newly treated patients: results from two randomized clinical trials. J Int Assoc Physicians AIDS Care (Chic). 2004;3:92-8.

96. Ofotokun I, Na LH, Landovitz RJ, Ribaudo HJ, McComsey GA, Godfrey C, et al. Comparison of the metabolic effects of ritonavir-boosted darunavir or atazanavir versus raltegravir, and the impact of ritonavir plasma exposure: ACTG 5257. Clin Infect Dis. 2015;60:1842-51.

97. Overton ET, Arathoon E, Baraldi E, Tomaka F. Effect of darunavir on lipid profile in HIV-infected patients. HIV Clin Trials. 2012;13:256-70.

98. Liang JS, Distler O, Cooper DA, Jamil H, Deckelbaum RJ, Ginsberg HN, et al. HIV protease inhibitors protect apolipoprotein B from degradation by the proteasome: a potential mechanism for protease inhibitor-induced hyperlipidemia. Nat Med. 2001;7:1327-31.

99. den Boer MAM, Berbee JFP, Reiss P, van der Valk M, Voshol PJ, Kuipers F, et al. Ritonavir impairs lipoprotein lipase-mediated lipolysis and decreases uptake of fatty acids in adipose tissue. Arterioscler Thromb Vasc Biol. 2006;26:124-9.

100. Maggi P, Bellacosa C, Carito V, Perilli F, Lillo A, Volpe A, et al. Cardiovascular risk factors in patients on long-term treatment with nevirapine- or efavirenz-based regimens. J Antimicrob Chemother. 2011;66:896-900.

101. Tebas P, Sension M, Arribas J, Duiculescu D, Florence E, Hung C-C, et al. Lipid levels and changes in body fat distribution in treatment-naive, HIV-1-Infected adults treated with rilpivirine or Efavirenz for 96 weeks in the ECHO and THRIVE trials. Clin Infect Dis. 2014;59:425-34.

102. Lazzarin A, Campbell T, Clotet B, Johnson M, Katlama C, Moll A, et al. Efficacy and safety of TMC125 (etravirine) in treatment-experienced HIV-1-infected patients in DUET-2: 24-week results from a randomised, double-blind, placebo-controlled trial. Lancet. 2007;370:39-48.

103. Orkin C, Squires KE, Molina J-M, Sax PE, Wong W-W, Sussmann O, et al. Doravirine/Lamivudine/ Tenofovir Disoproxil Fumarate is Non-inferior to Efavirenz/Emtricitabine/Tenofovir Disoproxil
Fumarate in Treatment-naive Adults With Human Immunodeficiency Virus-1 Infection: Week 48 Results of the DRIVE-AHEAD Trial. Clin Infect Dis Published Online First. 2018. https://doi.org/10. 1093/cid/ciy540.

104. Molina J-M, Squires K, Sax PE, Cahn P, Lombaard J, DeJesus E, et al. Doravirine versus ritonavir-boosted darunavir in antiretroviral-naive adults with HIV-1 (DRIVE-FORWARD): 48-week results of a randomised, double-blind, phase 3, non-inferiority trial. Lancet HIV. 2018;5:e211-20.

105. Quercia R, Roberts J, Martin-Carpenter L, Zala C. Comparative changes of lipid levels in treatmentnaive, HIV-1-infected adults treated with dolutegravir vs. efavirenz, raltegravir, and ritonavir-boosted darunavir-based regimens over 48 weeks. Clin Drug Investig. 2015;35:211-9.

106. Macias J, Mancebo M, Merino D, Tellez F, MontesRamirez ML, Pulido F, et al. Changes in liver steatosis after switching from efavirenz to raltegravir among human immunodeficiency virus-infected patients with nonalcoholic fatty liver disease. Clin Infect Dis. 2017;65:1012-9.

107. Gallant J, Lazzarin A, Mills A, Orkin C, Podzamczer $D$, Tebas P, et al. Bictegravir, emtricitabine, and tenofovir alafenamide versus dolutegravir, abacavir, and lamivudine for initial treatment of HIV-1 infection (GS-US-380-1489): a double-blind, multicentre, phase 3 , randomised controlled non-inferiority trial. Lancet. 2017;390:2063-72.

108. Sax PE, Pozniak A, Montes ML, Koenig E, DeJesus E, Stellbrink H-J, et al. Coformulated bictegravir, emtricitabine, and tenofovir alafenamide versus dolutegravir with emtricitabine and tenofovir alafenamide, for initial treatment of HIV-1 infection (GS-US-380-1490): a randomised, double-blind, multicentre, phase 3, non-inferiori. Lancet. 2017;390:2073-82.

109. MacInnes A, Lazzarin A, Di Perri G, Sierra-Madero JG, Aberg J, Heera J, et al. Maraviroc can improve lipid profiles in dyslipidemic patients with HIV: results from the MERIT trial. HIV Clin Trials. 2011;12:24-36.

110. Cooper DA, Cordery DV, Reiss P, Henry K, Nelson M, O'Hearn M, et al. The effects of enfuvirtide therapy on body composition and metabolic parameters over 48 weeks in the TORO body imaging substudy. HIV Med. 2011;12:31-9.

111. Platt L, Easterbrook P, Gower E, McDonald B, Sabin $\mathrm{K}$, McGowan C, et al. Prevalence and burden of HCV co-infection in people living with HIV: a global systematic review and meta-analysis. Lancet Infect Dis. 2016;16:797-808. 
112. Kralj D, Virovic Jukic L, Stojsavljevic S, Duvnjak M, Smolic M, Curcic IB. Hepatitis C virus, insulin resistance, and steatosis. J Clin Transl Hepatol. 2016;4:66-75.

113. Jackel-Cram C, Babiuk LA, Liu Q. Up-regulation of fatty acid synthase promoter by hepatitis $C$ virus core protein: genotype-3a core has a stronger effect than genotype-1b core. J Hepatol. 2007;46:999-1008.

114. Abid K, Pazienza V, de Gottardi A, Rubbia-Brandt L, Conne B, Pugnale $\mathrm{P}$, et al. An in vitro model of hepatitis $\mathrm{C}$ virus genotype 3a-associated triglycerides accumulation. J Hepatol. 2005;42:744-51.

115. Kumar D, Farrell GC, Fung C, George J. Hepatitis C virus genotype 3 is cytopathic to hepatocytes: reversal of hepatic steatosis after sustained therapeutic response. Hepatology. 2002;36:1266-72.

116. Wong VW-S, Wong GL-H, Chu WC-W, Chim AM-L, Ong A, Yeung DK-W, et al. Hepatitis B virus infection and fatty liver in the general population. J Hepatol. 2012;56:533-40.

117. Koethe JR, Jenkins CA, Lau B, Shepherd BE, Justice AC, Tate JP, et al. Rising obesity prevalence and weight gain among adults starting antiretroviral therapy in the United States and Canada. AIDS Res Hum Retroviruses. 2016;32:50-8.

118. Wong C, Gange SJ, Buchacz K, Moore RD, Justice AC, Horberg MA, et al. First occurrence of diabetes, chronic kidney disease, and hypertension among North American HIV-infected Adults, 2000-2013. Clin Infect Dis. 2017;64:459-67.

119. Promrat K, Kleiner DE, Niemeier HM, Jackvony E, Kearns M, Wands JR, et al. Randomized controlled trial testing the effects of weight loss on nonalcoholic steatohepatitis. Hepatology. 2010;51:121-9.

120. Dixon JB, Bhathal PS, Hughes NR, O'Brien PE. Nonalcoholic fatty liver disease: improvement in liver histological analysis with weight loss. Hepatology. 2004;39:1647-54.

121. Vilar-Gomez E, Martinez-Perez Y, Calzadilla-Bertot L, Torres-Gonzalez A, Gra-Oramas B, GonzalezFabian L, et al. Weight loss through lifestyle modification significantly reduces features of nonalcoholic steatohepatitis. Gastroenterology. 2015;149:365-7.

122. Ascha MS, Hanouneh IA, Lopez R, Tamimi TA-R, Feldstein AF, Zein NN. The incidence and risk factors of hepatocellular carcinoma in patients with nonalcoholic steatohepatitis. Hepatology. 2010;51:1972-8.

123. EASL-EASD-EASO Clinical Practice Guidelines for the management of non-alcoholic fatty liver disease. J Hepatol. 64:1388-1402.
124. Sanyal AJ, Chalasani N, Kowdley KV, McCullough A, Diehl AM, Bass NM, et al. Pioglitazone, vitamin E, or placebo for nonalcoholic steatohepatitis. N Engl J Med. 2010;362:1675-85.

125. Aghamohammadzadeh N, Niafar M, Dalir Abdolahinia E, Najafipour F, Mohamadzadeh Gharebaghi $\mathrm{S}$, Adabi $\mathrm{K}$, et al. The effect of pioglitazone on weight, lipid profile and liver enzymes in type 2 diabetic patients. Ther Adv Endocrinol Metab. 2015;6:56-60.

126. Li Z, Sun M, Wang F, Shi J, Wang K. Association between pioglitazone use and the risk of bladder cancer among subjects with diabetes mellitus: a dose-response meta-analysis. Int J Clin Pharmacol Ther. 2017;55:210-9.

127. Korhonen P, Heintjes EM, Williams R, Hoti F, Christopher S, Majak M, et al. Pioglitazone use and risk of bladder cancer in patients with type 2 diabetes: retrospective cohort study using datasets from four European countries. BMJ. 2016;354:i3903.

128. Shouhed D, Steggerda J, Burch M, Noureddin M. The role of bariatric surgery in nonalcoholic fatty liver disease and nonalcoholic steatohepatitis. Expert Rev Gastroenterol Hepatol. 2017;11: 797-811.

129. Furuya CKJ, de Oliveira CPMS, de Mello ES, Faintuch J, Raskovski A, Matsuda M, et al. Effects of bariatric surgery on nonalcoholic fatty liver disease: preliminary findings after 2 years. J Gastroenterol Hepatol. 2007;22:510-4.

130. Lundgren JD, Babiker AG, Gordin F, Emery S, Grund $B$, Sharma $S$, et al. Initiation of antiretroviral therapy in early asymptomatic HIV infection. N Engl J Med. 2015;373:795-807.

131. Saag MS, Benson CA, Gandhi RT, Hoy JF, Landovitz RJ, Mugavero MJ, et al. Antiretroviral drugs for treatment and prevention of HIV infection in adults: 2018 Recommendations of the International Antiviral Society-USA Panel. JAMA. 2018;320: 379-96.

132. French MA, King MS, Tschampa JM, da Silva BA, Landay AL. Serum immune activation markers are persistently increased in patients with HIV infection after 6 years of antiretroviral therapy despite suppression of viral replication and reconstitution of CD4 + T cells. J Infect Dis. 2009;200:1212-5.

133. Mendez-Lagares G, Romero-Sanchez MC, Ruiz-Mateos E, Genebat M, Ferrando-Martinez S, MunozFernandez MA, et al. Long-term suppressive combined antiretroviral treatment does not normalize the serum level of soluble CD14. J Infect Dis. 2013;207:1221-5. 
134. Guihot A, Dentone C, Assoumou L, Parizot C, Calin $\mathrm{R}$, Seang $\mathrm{S}$, et al. Residual immune activation in combined antiretroviral therapy-treated patients with maximally suppressed viremia. AIDS. 2016;30:327-30.

135. Crum-Cianflone N, Roediger MP, Eberly L, Headd $\mathrm{M}$, Marconi V, Ganesan A, et al. Increasing rates of obesity among HIV-infected persons during the HIV epidemic. PLoS ONE. 2010;5:e10106.

136. Younossi ZM, Loomba R, Rinella ME, Bugianesi E, Marchesini G, Neuschwander-Tetri BA, et al. Current and future therapeutic regimens for nonalcoholic fatty liver disease and nonalcoholic steatohepatitis. Hepatology. 2018;68:361-71.

137. Cariou B, Hanf R, Lambert-Porcheron S, Zair Y, Sauvinet V, Noel B, et al. Dual peroxisome proliferator-activated receptor alpha/delta agonist GFT505 improves hepatic and peripheral insulin sensitivity in abdominally obese subjects. Diabetes Care. 2013;36:2923-30.

138. Ratziu V, Harrison SA, Francque S, Bedossa P, Lehert $P$, Serfaty L, et al. Elafibranor, an agonist of the peroxisome proliferator-activated receptor-alpha and -delta, induces resolution of nonalcoholic steatohepatitis without fibrosis worsening. Gastroenterology. 2016;150(1147-1159):e5.

139. Gilead Sciences. Safety and efficacy of selonsertib in adults with nonalcoholic steatohepatitis (NASH) and bridging (F3) fibrosis (STELLAR 3).https:// clinicaltrials.gov/ct2/show/NCT03053050. Accessed 28 Sep 2018.

140. Wang P-X, Ji Y-X, Zhang X-J, Zhao L-P, Yan Z-Z, Zhang $\mathrm{P}$, et al. Targeting CASP8 and FADD-like apoptosis regulator ameliorates nonalcoholic steatohepatitis in mice and nonhuman primates. Nat Med. 2017;23:439-49.

141. Budas G, Karnik S, Jonnson T, Shafizadeh T, Watkins SBD. Reduction of liver steatosis and fibrosis with an ASK1 inhibitor in a murine model of NASH is accomplished by improvements in cholesterol, bile acid and lipid metabolism. J Hepatol. 2016;64(Suppl):170.
142. Loomba R, Lawitz E, Mantry PS, Jayakumar S, Caldwell SH, Arnold H, et al. The ASK1 inhibitor selonsertib in patients with nonalcoholic steatohepatitis: a randomized, phase 2 trial. Hepatology. Published Online First. 2017. https://doi.org/10. 1002/hep.29514.

143. Sanyal MF, Abdelmalek AM, Caldwell S, Diehl MLS. Efficacy and safety of simtuzumab for the treatment of nonalcoholic steatohepatitis with bridging fibrosis or cirrhosis: results of two phase $2 b$, doseranging, randomized, placebo-controlled trials. J Hepatol. 2017;66:S54.

144. Aramchol for HIV-associated Nonalcoholic Fatty Liver Disease and Lipodystrophy (ARRIVE).https:// clinicaltrials.gov/ct2/show/NCT02684591?cond=hi $\mathrm{v}+$ nafld\&rank $=2$.

145. Safadi R, Konikoff FM, Mahamid M, Zelber-Sagi S, Halpern M, Gilat T, et al. The fatty acid-bile acid conjugate Aramchol reduces liver fat content in patients with nonalcoholic fatty liver disease. Clin Gastroenterol Hepatol. 2014;12(2085-91):e1.

146. Tesamorelin Effects on Liver Fat and Histology in HIV.https://clinicaltrials.gov/ct2/show/NCT021968 31.

147. Fourman LT, Czerwonka N, Feldpausch MN, Weiss J, Mamputu J-C, Falutz J, et al. Visceral fat reduction with tesamorelin is associated with improved liver enzymes in HIV. AIDS. 2017;31:2253-9.

148. Stanley TL, Feldpausch MN, Oh J, Branch KL, Lee H, Torriani $\mathrm{M}$, et al. Effect of tesamorelin on visceral fat and liver fat in HIV-infected patients with abdominal fat accumulation: a randomized clinical trial. JAMA. 2014;312:380-9.

149. Schwarz J-M, Mulligan K, Lee J, Lo JC, Wen M, Noor $\mathrm{MA}$, et al. Effects of recombinant human growth hormone on hepatic lipid and carbohydrate metabolism in HIV-infected patients with fat accumulation. J Clin Endocrinol Metab. 2002;87:942. 